$\underline{\text { articles }}$

\title{
How SMEs Compete Against Global Giants Through Sustainable Competitive Advantages
}

\author{
Alexandra Galli-Debicella ${ }^{1}$ \\ 1 Department of Management, Ancell School of Business, Western Connecticut State University \\ Keywords: sustainable competitive advantage, competitiveness, generic strategies, core competency, scalability, small and medium enterprises \\ https://doi.org/10.53703/001c.29812
}

\section{Journal of Small Business Strategy}

Vol. 31, Issue 5, 2021

\begin{abstract}
Despite the influence and resources that large firms possess, small and medium size enterprises (SMEs) can find great success of their own when they find a niche with a sustainable competitive advantage. The literature has extensively discussed how SMEs can demand a price premium in a consumer segment based on focus differentiation. This paper explores how SMEs focus-based competitive advantage relies upon on competency-based factors that support their strategy. First, they have a non-scalable core competency that global firms cannot easily recreate due to their large size. Second, the emphasis for SMEs are on people or differentiation-based process core competencies, which also tend to be the most non-scalable. Third, SMEs find growth by shifting away from a niche to a differentiation strategy (if their core competency is scalable) or leveraging their non-scalable core competency to find a "string of opportunities" that are too small for large firms to notice separately, but taken together form a decent size business.
\end{abstract}

\section{Introduction}

In today's competitive economy, small and medium size enterprises (SMEs) have to confront global giants in the marketplace. Despite the daunting nature of this situation, there are numerous examples of small firms successfully competing against Fortune 500 companies. For example, micro and small craft beer companies have found prosperous niches to compete against larger, established companies (Alonso et al., 2017). Local bookstores continue to exist despite the ubiquitous presence of Amazon (Luyt \& Heok, 2015). Moreover, independent coffee shops meet the demands of their customers by offering specialty coffee, despite well-known coffee chains on many street corners (Carvalho et al., 2016). Although these examples represent firms competing in vastly different industries, what they share in common is the ability for small firms to find a prosperous niche.

Academic literature has examined this "niche strategy" in detail. Originally defined by Michael Porter as "focused" strategies for competitive advantage, SMEs have successfully incorporated the niche strategy as an effective way to compete against larger rivals (Porter, 1980, 1990a, 1990b). SMEs locate a consumer segment where they can command a price premium due to some differentiation more important to that segment than to others. These SMEs are able to build a defendable competitive advantage in these niches before larger competitors can develop a compelling propo- sition.

The question then is what organizational competencies enable this strategy? This paper examines the academic literature around SMEs and niche (focused) strategies, but then delves one level deeper to hypothesize the underlying competencies that enable said strategy. Specifically, two factors are at play, one internal and one external: developing a non-scalable core competency and finding a string of opportunities to leverage that competency.

Given the importance of SMEs, much of the literature has focused on their larger counterparts when studying competitive advantages and scalable core competencies. The limited literature that does exist on SMEs tend to focus on a particular firm (e.g. a case study). Despite the clear importance, few have investigated the impact of niche strategies for SMEs competing in a global context. Through combining the theoretical background on SMEs with the propositions around SMEs, this paper attempts to address this gap in the literature and advance extant knowledge.

The aim of this paper is to explore, analyze, and provide greater insight on how SMEs can create organizational competencies to define their niche strategy. Concepts affecting non-scalable core competencies and string of opportunities in SMEs are discussed and relevant propositions are made. Moreover, implications are explored, and future research directions are also identified. In particular, the outcomes of studying defendable competitive strategies have important implications for both theory and practice. Areas of the- 
ory impacted include small business success, organizational competencies, competitive advantage, as well as niche strategies. Practical implications include helping SMEs identify the best method to compete against larger firms by building a defendable competitive advantage. With this conceptual framework, the hope is for SMEs to successfully position and compete in a global market.

\section{Literature Review SME Definition and Unique Characteristics}

The definition for small and medium sized firms (sometimes referred to as "small businesses") are numerous in the literature and constantly evolving for institutions like governments and trade associations (Anastasia, 2015; Levenburg et al., 2005). Many researchers have traditionally classified by its size of revenue per year or the number of employees. Previous research has defined small and medium size enterprises within the Unites States as those with less than 500 employees (Anastasia, 2015; Blackford, 1991; Levenburg et al., 2005; Small Business Administration, 2019).

Thus, while most people would agree that a ten-person company with $\$ 1$ million falls in the category of "small", there could be debate as to whether a 100 person company with $\$ 100$ million in revenue is considered small, medium, or large. Since the size of employees is readily available, it is a widely used metric. For the purposes of this paper, the definition provided by the United States' Small Business Administration for SMEs, as firms with less than 500 employees, is applied (Small Business Administration, 2019).

SMEs have several unique and positive characteristics that distinguishes them apart from big businesses. SMEs tend to exhibit greater flexibility for developing and changing strategy, quicker decision making, and stronger ability to recognize market trends (Burns \& Stalker, 1961; Mintzberg, 1979, 1983; Rumelt et al., 1994). Nimbleness is inherent for most SMEs as they have less decision-makers and less complex processes. Therefore, SMEs can be faster and more flexible than bigger businesses. For example, SMEs can quickly adopt a new strategy in the face of changing market conditions as there is less processes for those firms to actually change (like organizational structure). Larger firms need to coordinate multiple complex functions and to gain approval from different groups of employees, while smaller firms in general communicate to a handful of employees and stakeholders (Burns \& Stalker, 1961; Mintzberg, 1979, 1983; Rumelt et al., 1994).

In addition to adapting strategies and tactics to changing marketplace conditions, SMEs can stay closer to both their customers and markets. SMEs are usually able to assimilate information gathered into their decision-making process both faster and more effectively than larger firms since they have less people (Burns \& Stalker, 1961; Mintzberg, 1979, 1983; Rumelt et al., 1994). Large firms may gather more raw information from the market, but that information may not be easily shared or in a timely manner with other employees within the firm. Nor will the right employees necessarily talk about it to synthesize conclusions from market data and take action. However, it is much easier for employees in small firms to internalize the same market information and problem solve around it together.

SMEs have several distinctive, yet disadvantageous characteristics that distinguishes them apart from big businesses as well. Specifically, SMEs tend to have more limited access to capital, cost benefits associated with scale, and expertise from specialized workforce (Mintzberg, 1979, 1983; Variyam \& Kraybill, 1993). Small and medium sized enterprises lack scale by their very definition. Since SMEs tend to have a higher cost base relative to their size than larger firms, they find low-cost strategies very difficult to pursue (Porter, 1980, 1990b). Moreover, managing the SMEs' business model for scaling is challenging. For example, research looked at how SMEs are unable to grow internationally through the digitization of the global economy because they were not designed to scale that way in the early stages of their existence (Bailetti \& Tanev, 2020; Westerlund, 2020).

SMEs also generally lack the same access to capital that large firms possess (Ang, 1992; Gray \& Jones, 2016; Jarillo, 1989; Neirotti et al., 2018; Petersen \& Rajan, 1994; Pfeffer \& Salancik, 1978; Stinchcombe, 1965; Vesper, 1990; Weinberg, 1994). In particular, SMEs find it difficult to access beyond a minor sum of capital, especially long-term capital, due to certain requirements of the capital market. Venture capitalists can offer a few select firms significant amounts of capital, but most of these firms have large aspirations of growth. Many SMEs also have the desire to grow, and thus need to turn to banks for capital-banks which typically have a relatively low tolerance for lending to risky new businesses. SMEs are thus less able to seize opportunities that could facilitate advancement of the firm (e.g. acquiring needed resources).

SMEs also tend to lack specialized skillsets from experts within their workforce. Their small resource pool encourages an environment of generalists (doing roles across traditional functions such as sales, marketing, finance, and general management) over specialists. Thus, the lack of job specialization prevents the firm from benefiting from competitively differentiated competency in certain areas (Mintzberg, 1979, 1983). SMEs also tend to have a loose division of labor as there are fewer formal practices in place, such as training or strategic planning (d'Amboise \& Muldowney, 1988; Haleem et al., 2019; Robinson \& Pearce, 1984; Welsch \& White, 1981). All of these unique characteristics derive from the smaller stature of these firms, not any industry-specific or geographic differences.

\section{Strategies for Competitive Advantages in SMEs}

Competitive advantage is the capability of a firm to perform some aspect of its work better than the competition. Competitive advantages for an organization are associated with sustained profits and above-average performance that exceed the average for the industry (Porter, 1985). According to the literature, certain generic strategies allow firms to gain a competitive advantage in the market based on three different options: cost leadership, differentiation, and focus (Porter, 1985, 1990a, 1990b).

The first generic strategy is cost leadership. SMEs seldom pursue a strategy of being the lowest cost provider in a market. Unfortunately, SMEs rarely benefit from economies of 
scale to reduce the cost structure (and therefore customer prices) far enough below the competition to gain market share (Hambrick et al., 1982; Woo \& Cooper, 1981). Two notable exceptions where SMEs might pursue a low-cost strategy are fragmented industry structures and proprietary technology. SMEs may be able to gain a cost advantage in a fragmented industry where no competitor can gain scale advantages (usually labor-based industries where no scale advantages exist) through operational excellence. Technology may also permit a lower cost structure for SMEs when that technology is incapable of imitation by their competition.

The next generic strategy is differentiation. Broad differentiation is usually the most successful strategy if an SME hopes someday to become a large enterprise (Wright, 1987). Broad differentiation usually takes the form of a superior product, service, or delivery characteristic that many customer segments seek over competitor value propositions-for which customers are often willing to pay a premium (Porter, 1980; Wright, 1987). SMEs who follow this competitive strategy will often be concerned about maintaining their differentiated position during their explosive growth-especially as larger firms will attempt to duplicate the differentiation strategy with greater resources.

The last generic strategy is referred to as the focus strategy. Focus, or niche, strategies are more commonly associated with SMEs than with large corporations (Dean et al., 1998; Porter, 1980). SMEs are more effective in adapting their offering to the needs of a particular consumer segment than bigger businesses as they can focus on a specific and narrower consumer segment. Large firms following a niche strategy must target numerous customer segments to achieve their large size, which becomes more challenging to tailor products and services to each segment (Wright, 1987). SME niche strategies typically have a differentiating aspect that meets the customer segment's needs. The aspect could be a unique product feature, a desired sales channel, or a superior service that the consumer segment values more than the rest of the market. As a result, SMEs can justify a higher price within this customer segment, leaving the price-sensitive consumer segments for bigger competitors.

\section{Niche Strategies in SMEs}

SMEs often begin by employing focus, or niche, strategies (Porter, 1985). SMEs and niche strategies are a natural fit, given the difficulty of employing broad based differentiation or even low cost strategies without an established brand or economies of scale. For example, research has looked at how family-owned SMEs reported success with international expansion when they pursued a high-quality niche strategy (Eddleston et al., 2019; Hennart et al., 2019). Cost leadership strategies, however, involve the scale for producing low per-unit costs that SMEs do not possess. Moreover, broad-based differentiation is possible for some medium sized businesses that have been in existence for several years, but usually not for small businesses that lack the resources to create a brand or distribution system for their differentiated products.

Therefore, SMEs can produce a differentiated product or service that aims at a smaller consumer group-which does not require scale or the resources for a broad brand or distribution system (Dean et al., 1998; Porter, 1980; Xie, 2018). Focus strategies often lead to a broader differentiation strategy for smaller firms growing into a medium-sized organization since they gain more resources needed to take their value proposition to a broader based population. As a result, SMEs can experience success pursuing focus strategies due to several key success factors: closeness to market, overlooked niche markets, greater flexibility in niche markets, and established niches,

Closeness to niche market. SMEs are nearer to the market and thus can more rapidly recognize consumer needs. Recognizing a consumer segment's unique needs before the competition is the most significant element in a successful niche strategy (Mintzberg, 1979, 1983). Since SMEs employ fewer employees, they can more easily communicate information and create insights from consumer interactions. These insights enable these firms to quickly realize the emergent consumer trends. Smaller firms also concentrate on fewer opportunities, relative to larger companies, which again enables their quickness (Burns \& Stalker, 1961; Mintzberg, 1979, 1983; Rumelt et al., 1994). As a result of being in close proximity to and knowledge of product customization needs for the local market, SMEs can grow quickly as a niche player (Campaniaris et al., 2015).

Overlooked niche markets. Global organizations often times overlook the consumer niche that appeal to SMEs. Large firms often have numerous priorities that require them to optimize where they invest valuable resources like time, money, and labor. Because of the sheer size focused opportunities offer, those opportunities may not have the same potential return as larger opportunities for low-cost strategies or broad-based differentiation (Chandler, 1990; Katrishen \& Scordis, 1998; Mintzberg, 1979, 1983).

Greater flexibility in niche markets. SMEs enjoy greater flexible in reaching a market niche, while larger companies struggle as they are often stuck in legacy systems (established processes, culture, and technology). Specifically, small firms are agile compared to their larger counterparts who are more prone to structural inertia, relying on existing products, prices, and cost positions (Cooper et al., 1986; Hannan \& Freeman, 1984; Xie, 2018). Therefore, small firms can distinguish themselves through agility and flexibility (Xie, 2018).

Focused consumer segments often have unique marketing factors relative to other consumer segments. For example, consumer niches may have exclusive distribution (e.g., specialty clothing stores) or specialized advertising (e.g., magazines targeting specific demographics) (Mintzberg, 1979, 1983). Since SMEs do not possess many "legacy systems" within their organization, they can become more malleable in meeting unique marketing factors (Poppo \& Zenger, 1998).

Established niches. Successful SMEs are typically established around a specific consumer niche. Start-ups often begin with an idea already targeted to a particular consumer group. For example, many local restaurants open with a specific demographic in mind. A specific example is eBay in its early days, which started as an auction site for collectables (Black, 2005). Many ideas are variations on old ideas that will appeal to a particular consumer segment 
more than the existing propositions on the market. Therefore, SMEs may offer a new functionality to a product, or a new image for a service that appeals to a targeted consumer base.

\section{Non-Scalable Core Competencies in SMEs}

SMEs can successfully pursue niche strategies due to their inherent benefits of "smallness" and their ability to leverage the key success factors listed above. However, not all SMEs are able to implement niche strategies. Identifying the attractive consumer segment, moving faster than big businesses, and adapting internal systems to the opportunity are all necessary, but not sufficient, capabilities for an SME to execute the focus strategy. Strong execution factors (identification, quickness, and flexibility) can also be true for larger firms, but SMEs are better positioned to successfully execute them because of their size. Therefore, this paper suggests there are further factors unique to SMEs that enable successful niche strategies.

The first factor is the creation of non-scalable core competencies. SMEs that are successful with niche strategies develop a competitive advantage that is sustainable when it cannot be copied by large firms. For a sustainable competitive advantage to exist, the differentiation valued by the focused consumer segment cannot be easily replicated by other firms (Porter, 1985) let alone by large firms who possess more resources than the SMEs. The key to sustainability is to have a core competency that incorporates both differentiation (that large firms cannot replicate) and nonscalability (the characteristic most likely to prevent replication since there are no advantages to scale). Below, both differentiation and non-scalability are discussed.

Core competencies are internal capabilities (Kak \& Sushil, 2002) and distinct skills (Hamel \& Prahalad, 1994; Prahalad \& Hamel, 1990) of a firm that enable a firm's competitive advantage (Kak \& Sushil, 2002; Porter, 1985). Core competencies can reside in the people, processes, or technology of a firm-and often a combination of the three (Chen \& Wu, 2006; Kak \& Sushil, 2002; Mascarenhas et al., 1998; Prahalad \& Hamel, 1990). Employees may have distinctive talents in the organization. Teams may exist that work together in creative ways. Processes may be more effective in certain organizations. Procter \& Gamble has a strong innovation process that allows it to get products to the market fast and make adjustments based on consumer response (Huston \& Sakab, 2006). Manufacturing or distribution processes may be more efficient and enable lower cost strategies. Wal-Mart's inventory and procurement processes allow it to pass lower costs onto consumers (Mann et al., 2015; Wheelen et al., 2018). Technology can also provide a core competency, as when sales forces utilize consumer databases to better target sales calls or enabling retailers to make better buying decisions (Mann et al., 2015; Walters, 1994). Core competencies tend to be complex, resulting from intertwined processes (or skills), people, and technologies that are difficult to replicate (Kak \& Sushil, 2002; Prahalad \& Hamel, 1990). Additionally, core competencies have several common characteristics: they take time to build, are unique relative to competition, and cannot easily be replicated (Porter, 1985; Prahalad \& Hamel, 1990).
Therefore, SMEs need to create core competencies that enable their focus strategies in a way that prevent larger and well-funded competitors from imitating them. The best approach for this is by finding core competencies that do not have advantages to scale. In other words, opportunities where larger firms cannot just spend more money on building the core competency and create a better result than small and medium sized enterprises would.

Scalability is lowering the cost per unit of a given item as the number of items produced increases (Kak \& Sushil, 2002; Porter, 1980, 1985). In regards to core competencies, this means that as the process, people, or technology increase in size, each incremental addition is cheaper than the last. One of the most scalable competitive advantage is a patent. Once a patent is completed and approved, it costs nothing to apply it as a company grows (Kak \& Sushil, 2002; Wheelen et al., 2018). One of the least scalable competitive advantage is individual talent. It is impossible to scale a "super-star" sales representative or "genius" R\&D researcher as a single employee can do so much. Most other competitive advantages fall somewhere on a continuum in between the two listed above, including having a strong corporate culture, operating superior manufacturing processes, or utilizing technology to manage $R \& D$ pipelines.

In order for competitive advantages to be successful, sustainability is necessary (Porter, 1980, 1985). For SMEs following a focus strategy, the key to sustainability is making sure that larger firms cannot simply enter the focused segment with superior resource levels. Non-scalable core competencies are the key to sustainability for an SME niche strategy. Thus, it is imperative for SMEs to have a competency that enables the niche differentiation (but not better at execution just because a larger company can do more of it). Accordingly, the paper proposes:

Proposition 1: SMEs with focused segment strategies will
establish their competitive advantage in non-scalable core
competencies.

However, the size of SMEs can become a threat to sustainability. For example, if the firm sustains a core competency based on the quality of their employees, there is the risk that those employees can leave for another job. For large firms who employ thousands of workers, this risk is mitigated by the sheer size of the work force relative to any individual. In micro-firms with a handful of employees, this risk to sustainability can be greatly impactful. Taken together, this paper proposes the following:

Proposition 2: People and differentiated process-based core competencies will be the most non-scalable for SMEs, although sustainability will be an issue over time.

\section{String of Opportunities}

Scale also plays a role in how SMEs can actually grow utilizing focus segment strategies. Any given focus segment, or niche, is inherently limited in its growth potential since there are a finite number of consumers with those distinctive needs (Porter, 1980). As a result, SMEs that successfully developed a competitive advantage in a focused segment have a couple of options for growth. First, they can take 
their niche advantage and try to generalize it to the broader market in a differentiation strategy (Porter, 1980, 1985). This is the common route for SMEs who are aspiring to become larger companies. SMEs take their original competitive advantage for the focused segment and determine which features of their differentiation will appeal to the broader market. They then take their products or service offerings and modify them to appeal to the broader market. It is worth mentioning that this option may not have been available to them at first given the capital constraints of an unproven business model or being a small company (Porter, 1980). For example, eBay started as a limited auction site for collectables and was popular among that focused consumer segment. Yet the management at eBay recognized that the same core competency (consisting of a distinctive technology with a built-in market of buyers and sellers) could be easily applied to the broader market with some modifications (Black, 2005; Wheelen et al., 2018). However, having a broad differentiation strategy requires scale in order to replicate the competitive advantage across many more consumer segments (Porter, 1980, 1985). Thus, SMEs who follow this growth strategy are more likely to have scalable core competencies that cannot be defended successfully by staying as a focused segment strategy. SMEs will have to widen their competitive advantage in order to preserve it. Therefore, the paper suggests:

Proposition 3: SMEs with scalable core competencies will grow by shifting to a differentiation strategy.

Broad differentiation is not always a possibility for SMEs that desire to grow. The differentiation that appeals to a given focused consumer segment might not be translatable into the broader market (Porter, 1980, 1985). However, that same core competency that the differentiation is based on could be incorporated to develop an additional differentiation for another focused customer segment. By pursuing multiple niche strategies, developing unique differentiation in each niche, another route for SMEs to grow is created. Prahalad and Hamel expressed the importance of core competencies being developed by firms through continuous improvements to not only achieve competitive advantage but to also take advantage of entering emergent markets (1990). Therefore, SMEs need to have a core competency that can be leveraged to build multiple types of niche advantages. For example, an SME that resells computer equipment to small businesses may have a sales force with a superior understanding of those consumer needs. The firm may consider entering a different product space like software customization based on that consumer understanding. Alternatively, the SME may consider targeting another niche that has comparable needs that the sales force could penetrate. The important objective is to leverage the core competency in different and new areas, when the actual competitive advantage is not translatable from the focused segment to the broader market. In effect, this becomes a "string of opportunities" for the SME, whereby each opportunity offers a unique differentiation to a unique consumer segment all based on a common non-scalable core competency. In sum, the paper suggests: will grow through leveraging the core competency across a string of niche opportunities.

\section{Discussion and Conclusion Non-Scalable Core Competencies and SMEs}

According to the first proposition, SMEs will earn greater success by following focused segment strategies when their competitive advantage is established from a non-scalable core competency. With a scalable core competency, larger firms will be able to develop a stronger competitive advantage than smaller firms and invade their niche. The key to why non-scalable competencies enable SME focused segment strategies lies in the underlying economics of such core competencies.

Since economies of scale are achieved through high fixed costs and low variable costs (Buzzell \& Gale, 1987; Porter, 1980), it is conceivable to assume that scalable core competencies tend to have a high fixed cost and low variable cost. Significant investment is made upfront in the competency, and then each incremental use of the competency has small investment associated with it. For example, an SAP system investment to enable sales force excellence typically requires a multi-million dollar investment upfront but a much lower on-going investment. Larger firms are more able to take advantage of scalable competencies because they can better afford the upfront investment (or, put another way, can afford any upfront investment a smaller company could). Therefore, the high fixed costs of scalable competencies do not create a barrier to entry for larger firms entering a focused segment of the market. Note that the reverse is true: a large firm with a scalable competency that enables a niche strategy can probably push out smaller firms due to the high initial fixed cost (Porter, 1980).

However, non-scalable competencies create a barrier for bigger businesses. Non-scalable competencies are those with low-fixed costs and high variable costs. For example, hiring an acclaimed sales person does not necessitate a great upfront investment (e.g., hiring expenditures), but the on-going expense (e.g., salaries, bonuses) is relatively significant. As a result, any company (large and small firms alike) could make the initial investment, and the investment to utilize the competency on each sale will be relatively high for small and large businesses alike. Large firms will not have an advantage over smaller firms if they both have the same non-scalable competency. This is because both small and large firms will face a high cost of utilizing the core competency.

Beyond this "neutrality" of non-scalable competencies for large firms and SMEs, large corporations are less likely to pursue the niche-base competitive advantage based on this competency. Large firms have numerous opportunities to consider and an opportunity in a focused segment (where they have no real superior core competency) that involves the elimination of an established SME, is not likely to be high on their list. The next logical question is what types of core competencies are either scalable or non-scalable-and thus which core competencies SMEs are more likely to pursue in building a niche competitive advantage.

| Proposition 4: SMEs with non-scalable core competencies 


\section{Scalability and Types of Core Competency}

According to the second proposition, sources of core competencies can be organized into three types: processbased, technology-based, or people-based (Chen \& Wu, 2006; Kak \& Sushil, 2002; Mascarenhas et al., 1998; Prahalad \& Hamel, 1990). Usually, a firm will have some combination of all three, but each type has a different level of "scalability". Technology-based competencies tend to be the most scalable. Process-based competencies may be scalable (if based in cost-advantage) or not (if based in differentiation). Lastly, people-based competencies tend to be the most difficult to scale owing to the inherent limitations of an individual.

Overall, technology-based competitive advantage tends to be the most scalable since the same technology can be utilized for numerous purposes and by multiple users. While technology is generally a very scalable advantage, it is also one that can be easily imitated by competitors (unless the technology is protected by a trademark, patent or the like). However, technology-based competitive advantage can be wrapped within process-based competency (firms that actually adopt unique processes to fully leverage their technology) (Mascarenhas et al., 1998).

Process-based competitive advantage may or may not be scalable even though they are generally the most sustainable. Process-based competitive advantages are generally very hard to develop or replicate. Processes are centered in a specific sequence of steps that are followed on a consistent basis (Russell, 2006). Processes that deliver competitive advantage have a unique sequence of steps that allow for lower costs or differentiation in the marketplace. Costbased process advantage tends to be scalable, while differentiation-based advantage tends not to be. Wal-Mart's supply chain processes are considered first class and benefit greatly from scale (Mann et al., 2015; Wheelen et al., 2018). Marketing, in addition to research and development, processes tend to have relatively fixed costs that can also benefit from scale (Buzzell \& Gale, 1987). Inventory and distribution processes can have high fixed costs (Porter, 1980) relative to other processes depending on industry, and thus tend to be more scalable. In contrast, processes that lead to high differentiation do not tend to be as scalable (Porter, 1980). Procter and Gamble maintain superior innovation processes that allows them to bring differentiated products to market faster than their competitors (Huston \& Sakab, 2006). However, to increase the capacity of this process requires a somewhat proportional increase in resources (i.e., consumer research, formula scientists, etc.) Thus, the process is relatively non-scalable. It is worth mentioning that scalability is not a binary measure. Scalability is thought of as being on a continuum from scalable (with no variable cost) to non-scalable (with all variable cost).

People-based competencies tend to be the least scalable as individual skills sets cannot be leveraged by more than one person. A company can hire a distinguished researcher or ten prominent researchers, but it will cost almost ten times more. Even though individual skill sets are not scalable, corporate cultures can be scalable. A culture that nurtures skills development, rewards excellence in perfor- mance, or promotes mentoring may be able to create people-based competencies. Culture is a more scalable people-based competency because the cost of adding an incremental person to it decreases over time.

Therefore, SMEs are better situated to utilize peoplebased competencies or process-based competencies with differentiation advantages (those with the lowest fixed costs and highest variable costs). SMEs can develop peoplebased advantages through hiring employees with superior skills for their particular niche. For example, sales people who understand how to sell to target consumers and scientists who know which product features consumers' value within the focused segment. Larger firms can do the same, but will find no real advantage over their smaller entrenched competitors. As a result, larger firms will be more apt to pursue bigger opportunities where they have more of a relative advantage as well as more of a return.

SMEs can also create process-based competencies to build differentiation advantages in their target focused segment. SMEs can build distribution systems that reach target consumers through their preferred channels, or may build a superior consumer research process that translates the niche's needs into product features or service offerings. Again, these processes are likely not very scalable as they are based in the particular unique characteristics of the focused segment and cannot be generalized to the full market.

However, the problem for SMEs with core competencies surrounds sustainability. While SMEs will tend to build a people or process based core competency, their small size makes sustaining that competency over time challenging. People-based competencies tend to be centered around a small number of employees within a SME, whereas a larger firm tends to have a deeper pool of talent that feeds into a culture of success. In a SME, the attrition of a single star employee could seriously injure a people-based core competency. Processes may also not be sustainable if they are founded in tacit knowledge (knowledge that is not written down, but only exists in people's head). If the core processes are based in tacit knowledge, and the employees with that tacit knowledge leave the SME, then the SME faces the same disproportionate risk to its core competency as it faces with people-based core competencies.

\section{SMEs and Strings of Opportunities}

With the third and fourth propositions, the goal of many SMEs is to grow beyond an SME to a larger company. Once an SME has successfully implemented a focus strategy based on a unique core competency, the question is how it can best grow beyond the niche it is targeting. SMEs are presented with two avenues to growth. First, they can take the differentiation they achieved in the focused segment and expand it to the broader market (essentially abandoning the niche strategy for a broad differentiation strategy). Second, SMEs can leverage the core competency underlying the original focused segment to enter into an adjacent focused segment (which essentially is adopting a "string of opportunities" strategy). The main aspect that determines which avenue the SME should take depends on the scalability of the core competency. Scalable core competencies are best matched with the broad differentiation strategy, while 
non-scalable core competencies are best matched with the string of opportunities strategy.

Scalable core competencies lead to broad differentiation strategies out of necessity. As described in Proposition 1, scalable core competencies are not defendable against larger firms. The SME with a scalable core competency is often forced to take their focus strategy to the broader market or eventually face a better-resourced, larger competitor invading their focused segment. SMEs might consciously utilize the original niche as a testing ground for the broader differentiation strategy, or may simply find that their original focused segment is not defendable (but a broader demand for their product or service exist). Technology-based competitive advantages (like Amazon) tend to move from niche strategies to broad differentiation very rapidly (Isckia, 2009; Taneja, 2018).

The strategy consisting of strings of opportunity are more common for SMEs who have non-scalable core competencies. Due to the non-scalable nature of the core competency, broad differentiation is not a realistic choice for most SMEs. SMEs would find it to be prohibitively expense unless there is strong demand in the broader market. Instead, SMEs need to find adjacent spaces where they can leverage the same core competency to meet the needs of a different focused consumer segment. For example, a local grocery store may branch out into an adjacent focused segment like ethnic foods and alcohol, where they can exploit their nonscalable core competency (e.g., people-based competency like excellent customer service). While SMEs with scalable competencies likely will only follow their focus strategy for a short amount of time before broadly differentiating, SMEs with non-scalable competencies can usually find success for a long time (and thus bide their time until the right adjacent opportunity is identified).

\section{Suggestions for Further Research and Conclusion}

Additional research should be pursued to better understand the propositions offered around SMEs and non-scalable core competencies. Specifically, a qualitative study of interviewing successful and not-so-successful SMEs pursu- ing focused segment strategies could reveal some of the qualitative factors underlying non-scalable core competencies and add more depth to the logical argument presented in this paper. Moreover, success measure studies could find the correlation of certain common core competencies and the success of SMEs (measured by survival rates, revenue/ profit growth, or profitability relative to their industry). Furthermore, economic modeling can be done for both small and large firms to compare the relative fixed and variable costs of different types of core competencies to determine which are truly more scalable, and if SMEs actually have an economic advantage for non-scalable core competencies. In addition, the SMEs and string of opportunities proposition should be further investigated through interviews and qualitative studies of how SMEs decide to expand based on the type of core competency they have. Lastly, the underlying economics of expansion should be modeled. Specifically researchers should look at the investments and returns for SMEs moving to a string of opportunities, versus a broad differentiation strategy.

In conclusion, this paper aims to stimulate the conversation around SMEs and niche (focused) strategies. The propositions proposed in the paper contribute to the overall investigation of developing a non-scalable core competency and finding a string of opportunities to leverage that competency for future research. Ultimately, more attention is needed to understand how important niche strategies are for small and medium sized organizations.

Through greater understanding, SMEs can improve their effectiveness in recognizing and appreciating the different ways that allows them to compete and succeed against their large rivals. By building a defendable competitive advantage before larger competitors can develop a compelling proposition, SMEs are able to build a defendable competitive advantage. Therefore, the propositions posed in this paper can raise awareness for firms when choosing their niche strategy, depending on what they hope to achieve, to promote the optimal journey of success for the business venture. 


\section{REFERENCES}

Alonso, A. D., Bressan, A., \& Sakellarios, N. (2017). Exploring innovation perceptions and practices among micro and small craft breweries. International Journal of Wine Business Research, 29(2), 140-158. htt ps://doi.org/10.1108/ijwbr-03-2016-0011

Anastasia, C. (2015). Exploring definitions of small business and why it is so difficult. Journal of Management Policy and Practice, 16(4), 88-99.

Ang, J. (1992). On the theory of finance for privately held firms. The Journal of Small Business Finance, 1(3), 185-203.

Bailetti, T., \& Tanev, S. (2020). Examining the relationship between value propositions and scaling value for new companies. Technology Innovation Management Review, 10(2), 5-13. https://doi.org/10.2 2215/timreview/1324

Black, G. (2005). Is eBay for everyone? An assessment of consumer demographics. S.A.M. Advanced Management Journal, 70(1), 50-60.

Blackford, M. G. (1991). Small business in America: A historiographic survey. Business History Review, 65(1), 1-26. https://doi.org/10.2307/3116903

Burns, T., \& Stalker, G. (1961). The management of innovation. Tavistock Publications.

Buzzell, R., \& Gale, B. (1987). The PIMS principles linking strategy to performance. The Free Press.

Campaniaris, C., Murray, R., Hayes, S., \& Jeffrey, M. (2015). Evidence-based development of a strategy for canadian apparel SMEs. Journal of Fashion Marketing and Management, 19(3), 299-314. https://doi.org/10.1 108/jfmm-11-2014-0079

Carvalho, J. M., Paiva, E. L., \& Vieira, L. M. (2016). Quality attributes of a high specification product: Evidences from the speciality coffee business. British Food Journal, 118(1), 132-149. https://doi.org/10.110 8/bfj-02-2015-0059

Chandler, A. (1990). Scale and scope: The dynamics of industrial capitalism. Harvard University Press.

Chen, Y., \& Wu, T. (2006). The conceptual construction of core competence for two distinct corporations in Taiwan. Journal of American Academy of Business, 8(1), 197-202.

Cooper, A. C., Willard, G. E., \& Woo, C. Y. (1986). Strategies of high-performing new and small firms: A reexamination of the niche concept. Journal of Business Venturing, 1(3), 247-260.

d'Amboise, G., \& Muldowney, M. (1988). Management theory for small business: Attempts and requirements. Academy of Management Review, 13(2), 226-240. https://doi.org/10.5465/amr.1988.4306873

Dean, T. J., Brown, R. L., \& Bamford, C. E. (1998). Differences in large and small firm responses to environmental context: Strategic implications from a comparative analysis of business formations. Strategic Management Journal, 19(8), 709-728. https://doi.org/1 0.1002/(sici)1097-0266(199808)19:8
Eddleston, K. A., Sarathy, R., \& Banalieva, E. R. (2019). When a high-quality niche strategy is not enough to spur family-firm internationalization: The role of external and internal contexts. Journal of International Business Studies, 50(5), 783-808. https://doi.org/10.10 57/s41267-018-0199-8

Gray, D., \& Jones, K. F. (2016). Using organisational development and learning methods to develop resilience for sustainable futures with SMEs and micro businesses: The case of the "business alliance." Journal of Small Business and Enterprise Development, 23(2), 474-494. https://doi.org/10.1108/jsbed-03-201 5-0031

Haleem, F., Jehangir, M., \& Ullah, Z. (2019). Strategic planning and SMEs performance: A developing country's perspective. Journal of Business \& Economics, 11(2), 33-49.

Hambrick, D., MacMillan, I., \& Day, D. (1982). Strategic attributes and performance in the BCG matrix: A PIMS-based analysis of industrial product business. Academy of Management Journal, 25, 510-531.

Hamel, G., \& Prahalad, C. (1994). Competing for the future. Harvard Business School Press.

Hannan, M., \& Freeman, J. (1984). Structural inertia and organizational change. American Sociological Review, 49(2), 149-164.

Hennart, J.-F., Majocchi, A., \& Forlani, E. (2019). The myth of the stay-at-home family firm: How familymanaged SMEs can overcome their internationalization limitations. Journal of International Business Studies, 50(5), 758-782. http s://doi.org/10.1057/s41267-017-0091-y

Huston, L., \& Sakab, N. (2006). Connect and develop: Inside Procter \& Gamble's new model for innovation. Harvard Business Review, March, 60-72.

Isckia, T. (2009). Amazon's evolving ecosystem: A cyberbookstore and application service provider. Canadian Journal of Administrative Sciences, 26(4), 332-343. htt ps://doi.org/10.1002/cjas.119

Jarillo, J. C. (1989). Entrepreneurship and growth: The strategic use of external resources. Journal of Business Venturing, 4(2), 133-147. https://doi.org/10.1016/088 3-9026(89)90027-x

Kak, A. \& Sushil. (2002). Sustainable competitive advantage with core competence: A review. Global Journal of Flexible Systems Management, 3(4), 23-38.

Katrishen, F. A., \& Scordis, N. A. (1998). Economies of scale in services: A study of multinational insurers. Journal of International Business Studies, 29(2), 305-323. https://doi.org/10.1057/palgrave.jibs.84900 $\underline{38}$

Levenburg, N., Schwarz, T., \& Motwani, J. (2005). Understanding adoption of internet technologies among SMEs. Journal of Small Business Strategy, 16(1), 51-69. 
Luyt, B., \& Heok, A. (2015). David and Goliath: Tales of independent bookstores in Singapore. Publishing Research Quarterly, 31(2), 122-131. https://doi.org/1 0.1007/s12109-015-9402-y

Mann, M., Byun, S.-E., \& Li, Y. (2015). Realignment strategies in the US retail industry during a recessionary time. International Journal of Retail \& Distribution Management, 43(8), 775-792. https://do i.org/10.1108/ijrdm-11-2014-0151

Mascarenhas, B., Baveja, A., \& Jamil, M. (1998). Dynamics of core competencies in leading multinational companies. California Management Review, 40(4), 117-133. https://doi.org/10.2307/41165 $\underline{967}$

Mintzberg, H. (1979). The Structuring of organizations. Prentice-Hall.

Mintzberg, H. (1983). Structure in fives: Designing effective organizations. Prentice-Hall.

Neirotti, P., Raguseo, E., \& Paolucci, E. (2018). How SMEs develop ICT-based capabilities in response to their environment. Journal of Enterprise Information Management, 31(1), 10-37. https://doi.org/10.1108/iei m-09-2016-0158

Petersen, M. A., \& Rajan, R. G. (1994). The benefits of lending relationships: Evidence from small business data. The Journal of Finance, 49(1), 3-38. https://doi.o rg/10.1111/j.1540-6261.1994.tb04418.x

Pfeffer, J., \& Salancik, G. (1978). The external control of organizations: A resource dependence perspective. Harper and Row.

Poppo, L., \& Zenger, T. (1998). Testing alternative theories of the firm: Transaction cost, knowledgebased, and measurement explanations for make-orbuy decisions in information services. Strategic Management Journal, 19(9), 853-877. https://doi.org/1

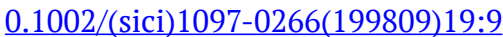

Porter, M. E. (1980). Competitive strategy: Techniques for analyzing industries and competitors. Free Press.

Porter, M. E. (1985). Competitive advantage: Creating and sustaining superior performance. Free Press.

Porter, M. E. (1990a). The competitive advantage of nations. Free Press.

Porter, M. E. (1990b). New global strategies for competitive advantage. Planning Review, 18(3), 4-14. https://doi.org/10.1108/eb054287

Prahalad, C., \& Hamel, G. (1990). The core competence of the corporation. Harvard Business Review, 68(3), 79-91.

Robinson, R. B., Jr., \& Pearce, J. A., II. (1984). Research thrusts in small firm strategic planning. The Academy of Management Review, 9(1), 128. https://doi.org/10.23 $\underline{07 / 258239}$
Rumelt, R., Schendel, D., \& Teece, D. (1994). Fundamental issues in strategy: A research agenda. Harvard Business School Press.

Russell, J. (2006). Process auditing and techniques. Quality Progress, 39(6), 71-75.

Small Business Administration. (2019, October). Organization. https://www.sba.gov/about-sba/organiz ation

Stinchcombe, A. (1965). Social structure and organizations: Handbook of organizations. Rand McNally.

Taneja, H. (2018). The end of scale. MIT Sloan Management Review, 59(3), 67-72.

Variyam, J. N., \& Kraybill, D. S. (1993). Small firms' choice of business strategies. Southern Economic Journal, 60(1), 136-146. https://doi.org/10.2307/1059 $\underline{938}$

Vesper, K. (1990). New venture strategies (revised). Prentice Hall.

Walters, D. (1994). The impact of the recession on retailing management decisions and performance. International Journal of Retail \& Distribution Management, 22(4), 20-31. https://doi.org/10.1108/09 $\underline{590559410062681}$

Weinberg, J. (1994). Firm size, finance, and investment. Federal Reserve Bank of Richmond Economic Quarterly, 80(1), 19-40.

Welsch, J., \& White, J. (1981). A small business is not a little big business. Harvard Business Review, 59(4), $18-32$.

Westerlund, M. (2020). Digitalization, internationalization and scaling of online SMEs. Technology Innovation Management Review, 10(4), 48-57. https://doi.org/10.22215/timreview/1346

Wheelen, T., Hunger, J., Hoffman, A., \& Bamford, C. (2018). Concepts in strategic management and business policy: Globalization, innovation and sustainability (15th ed.). Pearson.

Woo, C. Y., \& Cooper, A. C. (1981). Strategies of effective low share businesses. Strategic Management Journal, 2(3), 301-318. https://doi.org/10.1002/smj.42 $\underline{50020307}$

Wright, P. (1987). A refinement of Porter's strategies. Strategic Management Journal, 8(1), 93-101. https://d oi.org/10.1002/smj.4250080108

Xie, C. (2018). How do small firms compete? A demandbased perspective. Journal of Management Policy and Practice, 19(1), 26-34. 